Journal of Social Sciences 4 (4): 343-346, 2008

ISSN 1549-3652

(C) 2008 Science Publications

\title{
The Social Adjustment of the Kuy People to a Multicultural Context in Southern Isan, Thailand
}

\author{
${ }^{1}$ Wilart Pothisan, ${ }^{1}$ Art Nantajak, ${ }^{2}$ Prasopsuk Rittidet and ${ }^{3}$ Budsakorn Saenyabud \\ ${ }^{1}$ Faculty of Humanities and Social Science, Mahasarakham University, Thailand \\ ${ }^{2}$ Faculty of Education, Rajabhat Mahasarakham University, Thailand \\ ${ }^{3}$ Faculty of Humanities and Social Science, Rajabhat Mahasarakham University, Thailand
}

\begin{abstract}
The state had paid much attention on economy by building a network of roads between the province, the district and the village for the Kuy people in Ban Treum. The state established a health center to provide for the people with modern medical care and malaria prevention. And the external streams had more effects on their communities. Therefore, Kuy had to adjust themselves The purposes of the study were to study the social adjustment in multicultural context before world war II (Before 1945) and to study the social adjustment in multicultural context after world war II (1945-1976). The area of the study was Ban Truem, Si Khoraphum district, Surin province. The data were elicited through a document analysis and interviews as well as participatory and non-participatory observation of 30 key informants, comprising aged people, officially-appointed community leaders, ritual performers and officials from government and private sectors. The data were analyzed with the use of qualitative analysis method, the results being presented by means of descriptive analysis as follows. First period they created freedom ways of life, highly believed in custom, tradition and ancestor worship since an ancient period to after World War II (1945). The Kuy people in Ban Treum had a strong belief in ancestral spirit was still found in all Kuy villagers. Before the end of World War II (before 1945). Kuy adjusted themselves freely according to their traditional mores and rituals regarding ancestral spirits. Their settlement patterns fitted well with environmental conditions. In general, their social practices were based on mores. Kuy earned a living by farming for homeconsumption, weaving, raising animals and fishing. They tried to be familiar with the surrounding systems, began commercial rice farming and sold paddy to merchants along the railway. In second period (1945-1976) they built and adjusted their relation with Thai-Cambodians ethnic and Thai-Isan by married, farmed, accepted and believed in Buddhism along with ancestor soul and the government aimed at modernization, so capitalism had become more influential on socio-economic conditions. Internal capitals were accumulated from different kinds of businesses and inheritance, while most foreign capitals gained much support from various state policies and measures. By the time the 8th and 9th National Development Plans were applied, capitalism had already established firmly in Thai economy. However, the Kuy people had a strong belief in Phi Takuat", the symbol of fertility. They performed annually in the 6th month before planting rice. A tail of monitor lizard, a symbol of fertility, was used to tell the fortune. This ritual was practiced in parallel with capitalism, reflecting the fight for ecological conservation and sending the message that natural resources should be of major concern in any way of life.
\end{abstract}

Key words: The adjustment, the social adjustment, the Kuy, multicutural context, Southern Isan, Thailand

\section{INTRODUCTION}

Kuy was one ethnic group in Southern Isan (Northeast of Thailand), Southern Laos and Northern Cambodia along the Phanom Dong Rek. They settled down in groups between the Phanom Dong Rek and the Mun River, while building relationship with other ethnic groups like Khmer and Lao. Kuy spoke a language in Mon-Khmer family and called themselves by their accent as "Kuy or Kuai" which meant people. "Kuy Malo or Melo or Malua" earned their living as farmers; "Kuy Dam Rey" caught and tamed wild elephants; "Kuy Bru" lived in a highland or mountainous area. "Bru" meant mountain. Thai and 
Thai-Isan (Laos) people called Kuy "Suai" or "Kha". Kuy adjusted themselves well enough to speak different languages of their neighboring ethnic groups such as Khmer-Suai and Lao-Suai ${ }^{[1]}$. They earned a living in various forms according to their surrounding topography liked collecting forest products, growing rice and field crops, gardening, raising animals, making pots and iron products. Moreover, The Kuy females were skillful in weaving. In 1985, 9.59\% of Surin people were Kuy, 9.20\% were a mix of Thai-Isan and Kuy and 3.15 were a mix of Thai-Khmer and Kuy ${ }^{[1]}$ Malua in Ban Truem of Si Khoraphum district in Surin province. The state had paid much attention on economy by building a network of roads between the province, the district and the village for the Kuy people in Ban Treum. The state established a health center to provide for the people with modern medical care and malaria prevention. There were trucks carrying passengers and farm products from the village to the market in Si Khoraphum District. However,The Kuy people in Ban Treum believed in San (spirit house) Phi Takuat", the symbol of fertility. The Kuy people adjusted themselves by paying more attention on importance events of Buddhism, culture and tradition. Gradually, The Kuy people had adjusted their way of life to become Buddhists. This new kind of power reflected the forms of Kuy's relationship which were transferred from generation to generation and united with nature and ancestral spirits. It also showed that Kuy adjusted their relationship with other ethnic groups of Thai-Isan (Laos) and Thai-Khmer (Khmer), while developing the "rice culture and fish culture", based on their accumulated experience. Such adjustment reflected Kuy's establishment of socio-economic relationship and "community culture" which had existed for a long period of time.

\section{The social adjustment in multicultural context by} super natural power:

The social adjustment in multicultural context before world war II (Before 1945): The Kuy people in Ban Treum had adjusted gradually when Thai-Isan migrated to Southern Isan, Kuy started to build their relationship with Thai-Isan by accepting Buddhism and developing a new set of local wisdom tended to change their culture much slower. Thus, it took them a very long time to change their belief in spirits and become Buddhist, to build temples and to learn how to read and write. Kuy still held their traditional belief strongly although Thai state and local religious leaders prohibited any forms of beliefs in spirits “... such as Phi Thai, Phi Fa, Phi Mahesak Lak Mueang, Phi Pop. Believers would be subjected to trial and be fined
12 baht once found guilty. If they could not afford the fine, they would be sentenced to jail for one month. Informants would get a reward from the government. Later on, there was a royal command for legislation on spirit in 1856". A strong belief in ancestral spirit was still found in all Kuy villages. Before the end of World War II (before 1945) Kuy adjust themselves freely according to their traditional mores and rituals regarding ancestral spirits. Their settlement patterns fit well with environmental conditions. In general, their social practices were based on mores. Kuy earned a living by farming for home-consumption, weaving, raising animals and fishing. They tried to be familiar with the surrounding systems, began commercial rice farming and sold paddy to merchants along the railway during 1926-1945.

The social adjustment in multicultural context by depending on nature after world war (1945): The adjustment in Ban Truem was mainly based on its environment. When there was drought, people migrated to a more fertile area. This action was called "move to a new home" such as Ban Huai Po and Ban Saen Suk in Huai Thalaeng district of Nakhon Ratchasima province, as well as Ban Non Daeng of Nong Teng Sub-district in Buri Ram province. Some villagers moved out to find a second job for additional income like working as paid labor at Mr. Kiat's saw mill located near a railway at Ban Kalan Station or in some sugar plantations of Chon Buri province. In Ban Truem, the state had paid much attention on economy by building a network of roads between the province, the district and the village. A health station was established to provide people with modern medical care and malaria prevention. There were trucks carrying passengers and farm products from the village to the market in Si Khoraphum district. Rice growing areas were modified and expanded. Primary education after grade 4 was provided. There were some rice mills in villages. People practiced such supernatural rituals as telling the fortune from the tail of Takuat (Monitor lizard) to ask for fertility from nature, or performing "Kael Mo" for health protection. Villagers paid more attention on important events of Buddhism, culture, tradition and belief. Teachers were local leaders in socio-economic adjustment. The state required villagers' cooperation on the matter of national security against the communists.

The social adjustment in multicultural context by alternative: The government aimed at modernization, so capitalism had become more influential on socioeconomic conditions. Internal capitals were accumulated from different kinds of businesses and 
inheritance, while most foreign capitals gained much support from various state policies and measures. By the time the 8th and 9th National Development Plans were applied, capitalism had already established firmly in Thai economy. Moreover, rural development made people destroy forests for more farmland. During mid 1970s, there was no more land to be claimed. Thus, some people, particularly the young ones, had no way out but migrated to find jobs in the cities. Community institutions were much affected, especially on their culture. Money became a major part in people's relationship at the household, community and national levels. Later on, His Majesty the King proposed a new theory called "Self-Sufficient Economy"[2]. with the main purpose of "having enough to eat and support themselves". The Kuy villagers in Ban Truem were mainly farmers and developed certain annual rituals relating to rice farming. The remarkable one called "San Phi Pu Ta Takuat" was performed annually in the 6th month before planting rice. A tail of monitor lizard, a symbol of fertility, was used to tell the fortune. This ritual was practiced in parallel with capitalism, reflecting the fight for ecological conservation and sending the message that natural resources should be of major concern in any way of life. Water in canals came from natural rainwater and acted as a "source of rice culture and fish culture". When the environment changed, villagers in Ban Truem also adjusted their farming practice by digging a fish pond for homeconsumption and raising animal in the dry season. In addition, although people moved to work outside, they always came back home during the rice planting season $^{[2]}$. They were able to estimate whether or not they would have enough rice supply or some surplus.

\section{MATERIALS AND METHODS}

The social adjustment of the Kuy people to a multicultural context in Southern Isan was divided two periods are an ancient period to after World War II (1945) and second period (1945-1976). To study cultural relation of the Kuy people in Ban Truem, Si Khoraphum district, Surin province. The data were elicited through interviews as well as participatory and non-participatory observation of 30 informants, comprising aged people, officially-appointed community leaders, ritual performers and officers from government and private sectors. The data were analyzed with the use of qualitative analysis method, the results being presented by means of descriptive analysis.

\section{RESULTS}

The social adjustment in multicultural context before world war II (Before 1945), the Kuy people adjusted themselves by respected "San $\mathrm{Phi} \mathrm{Pu}$ Ta Takuat", the symbol of fertility. It was the supernatural power. Kuy adjusted themselves freely according to their traditional mores and rituals regarding ancestral spirits. Their settlement patterns fit well with environmental conditions. In general, their social practices were based on mores. Kuy earned a living by farming for home-consumption, weaving, raising animals and fishing. They tried to be familiar with the surrounding systems, began commercial rice farming and sold paddy to merchants along the railway. They adjusted themselves to the ecological. The social adjustment in multicultural context after world war II (1945-1976). After 1945, external streams had more effects on their communities. Therefore, Kuy had to adjust themselves to Kuy culture were "Phi (spirit), Buddhism and Brahmanism". Phi were their ancestral spirits and Kuy also developed their beliefs in relation to the supernatural. Kuy Malua in Ban Truem of Si Khoraphum District in Surin Province believed in San (spirit house) Phi Takuat", the symbol of fertility. And they adjusted themselves to the social adjustment in multicultural context by alternative to survive like finding jobs in the cities for more income. Kuy in Ban Truem grew mono crop of rice for sale. They held strong community belief in "San Pu Ta Takuat". People accepted new technologies while money played more active role in their way of life. School provided education up to grade 12. More than twenty farmers owned private trucks. They acted as middlemen in buying paddy from other villages and created a patronage relationship with merchants at Kalan Market. Although villagers practiced modern rice farming, they still kept cattle for sale.

\section{DISCUSSION}

The main elements of Kuy culture were "Phi (spirit), Buddhism and Brahmanism". Phi were their ancestral spirits and Kuy also developed their beliefs in relation to the supernatural. Kuy Malua in Ban Truem of Si Khoraphum District in Surin Province believed in San (spirit house) Phi Takuat", the symbol of fertility. Kuy Dam Rey in Ban Kra Pho-Ta Klang of Tha Tum District in Surin Province held belief in "San Phi Pakam, ${ }^{,[1]}$ for their safety and luck. This new kind of power reflected the forms of Kuy's relationship which were transferred from generation to generation and united with nature and ancestral spirits. It also showed that Kuy adjusted their relationship with other ethnic groups of Thai-Isan (Lao) and Thai-Khmer (Khmer), while developing the "rice culture and fish culture", based on their accumulated experience ${ }^{[3]}$. Such 
adjustment reflected Kuy's establishment of socioeconomic relationship and "community culture" which had existed for a long period of times.

\section{CONCLUSION}

The social adjustment of the Kuy in multicultural context was the dynamic adjustment and related to their area. They built relationship with neighboring ethnic groups, the state and capitalists. They accumulated experience, recollection, history and group awareness. Relationships among group members were identified clearly under state administration system. Kuy in Ban Truem had their own history and used their local wisdom to adjust themselves for survival. Geographically, Ban Truem was located on a highland. Villagers created "San Pu Ta Takuat" and the use of monitor lizard's tail to tell the fortune. They consciously practiced their rituals in parallel with state development policies. At the present, some people from Ban Truem migrated to find new farmland in Buri Ram and Nakhon Ratchasima. The external streams had more effects on their communities. Therefore, Kuy had to adjust themselves to survive like finding jobs in the cities for more income. People accepted new technologies while money played more active role in their way of life and the Kuy in Ban Treum adjusted themselves to be a labor. The Kuy people in Ban Truem grew mono crop of rice for sale. They held a strong community belief in "San $\mathrm{Pu}$ Ta Takuat".The Kuy people in Ban Treum learned to adjust themselves to the environment, the social, the social context and the multicultural context though the Phi Ta Kuat ritual.

\section{ACKNOWLEDGEMENT}

The researchers express their sincere appreciation for all of support provided.

\section{REFERENCES}

1. Seidenfaden, E., 1952. The Kui people of Combodia and Siam. J. Siam Soc., 39: 144-180.

2. Sati, P., J. Dhamawat, P. Pratepha and S. Rittidech, 2005. Changes in the conscious mind in applying technology for growing rice at the Chee River Basin in Northeastern of Thailand. J. Soc. Sci., 1 : 172-177. http://www.scipub.org/fulltext/jss/jss13172-177.pdf.

3. Prasopsuk, R., P. Piampongsan, P. Prathepha and B. Yodmalee, 2005. The development of community economic system of Thung Kula Ronghai Famers at Ban Ta Yuak, Northeastern Thailand. J. Soc. Sci., 1: 240-242. http://www.scipub.org/fulltext/jss/jss14240-242.pdf. 